\title{
Voluntary Feed Intake of Goats Supplemented with Different Dietary Fats
}

\author{
Niel L. Ningal
}

\begin{abstract}
Three (3) female (rumen-cannulated goats) weighting $27.33 \pm 1.53 \mathrm{~kg}$ were housed in individual elevated metabolism stalls provided with $30 \%$ concentrate in the morning based on feed requirements (3\% of their body weight (BW) dry matter (DM) basis) of the animals. Ad libitum feeding of napier grass follows thereafter. Clean drinking water were made available all the times in the respective animal watering troughs.
\end{abstract}

All data were collected sequentially in every cycle of the study. There were $\mathbf{7}$ days lag period in every cycle for the animals to return to each natural state. On the $8^{\text {th }}$ day of every cycle animals were given different dietary treatment. Voluntary feed intakes were recorded for 3 days. This was done on the $11^{\text {th }}$ to $13^{\text {th }}$ day of feeding trial ( 3 days after treatment).

The following were data collected, daily roughage dry matter intake (g/ kg metabolic body weight), daily concentrate feed intake (g DM/kg MBW) and daily total feed dry matter intake (g DM/ kg MBW).

All data collected showed no significant difference $(P>0.05)$ among treatment means was observed. This implies that supplementing 3 to 5\% dietary fats from two different sources (VCO and Lard) in ruminant diet do not influence the roughage, concentrate and total feed intake of mature female goats.

\section{INTRODUCTION}

An obvious reason for supplementing ruminant diets with fat is to increase the energy density of the animal's diet. Fatty acids yield more energy than other organic nutrients when metabolized by the animal (Hess et al, 2008). On their research conducted in order to elucidate the effects of supplemental fat on utilization of other dietary components on ruminants. Negative associative effects are not likely to be observed in ruminants consuming foragebased diets with supplemental fat at $\leq 2 \%$ of DMI. Moreover, inclusion of supplemental fat at $\leq 3 \%$ of DM is recommended to obtain the most benefit from the energy contained within the fat and other dietary components in high-forage diets. For ruminants fed high-concentrate diets, supplementing fat at $6 \%$ of diet DM is expected to have minimal impacts on utilization of other dietary components. Although there is greater potential to supply the ruminant animal with unsaturated fatty acids from dietary origin if fat is added to high-concentrate diets, incomplete ruminal biohydrogenation of $\mathrm{C} 18$ unsaturated fatty acids results in an increase in duodenal flow of 18:1 trans fatty acids regardless of basal diet consumed by the animal.
A variety of fat supplements is available today for ruminant nutritionists to use. These include various commodity fats such as lard and coconut oil. Thus, this study was conducted in order to evaluate the effect of dietary fats on voluntary feed intake of mature female goats.

\section{MATERIALS AND METHODS}

Three (3) female (rumen-cannulated goats) weighting $27.33 \pm 1.53 \mathrm{~kg}$ were housed in individual elevated metabolism stalls provided with $30 \%$ concentrate in the morning based on feed requirements (3\% of their body weight (BW) dry matter (DM) basis) of the animals. Ad libitum feeding of napier grass follows thereafter. Clean drinking water were made available all the times in the respective animal watering troughs.

All data were collected sequentially in every cycle of the study. There were 7 days lag period in every cycle for the animals to return to each natural state.

On the $8^{\text {th }}$ day of every cycle animals were given different dietary treatment. Voluntary feed intakes were recorded for 3 days. This was done on the $11^{\text {th }}$ to $13^{\text {th }}$ day of feeding trial (3 days after treatment).

\section{RESEARCH DESIGN AND LAY-OUT}

Three mature goats surgically fitted with rumen cannula were used. The experimental animals were in good body condition prior to and throughout the duration of the study. Complete Randomized Design (CRD) was used to evaluate the effect of different dietary treatments. Five dietary treatments were used in the study with dietary treatment combinations as follows.

\section{$>$ Treatment Combinations}

The rumen-cannulated goats were supplemented with different levels of two dietary fat sources with dietary treatment combinations as follows.
- Treatment 1 -

- Treatment 2 -

- Treatment 3 -

- Treatment 4 -

- Treatment 5 -
CONTROL $3 \%$ Virgin Coconut Oil (VCO) $5 \%$ Virgin Coconut Oil (VCO) $3 \%$ Lard $3 \%$ Lard 
ISSN No:-2456-2165

\begin{tabular}{|c|c|c|c|c|c|}
\hline Treatment & Initial & $\begin{array}{c}1^{\text {st }} \\
\text { Cycle }\end{array}$ & $\begin{array}{c}2^{\text {nd }} \\
\text { Cycle }\end{array}$ & $\begin{array}{c}3^{\text {rd }} \\
\text { Cycle }\end{array}$ & $\begin{array}{c}4^{\text {th }} \\
\text { Cycle }\end{array}$ \\
\hline Animal 1 & $\mathrm{T} 3$ & $\mathrm{~T} 2$ & $\mathrm{~T} 5$ & $\mathrm{~T} 4$ & $\mathrm{~T} 1$ \\
\hline Animal 2 & $\mathrm{T} 2$ & $\mathrm{~T} 3$ & $\mathrm{~T} 4$ & $\mathrm{~T} 1$ & $\mathrm{~T} 5$ \\
\hline Animal 3 & $\mathrm{T} 5$ & $\mathrm{~T} 4$ & $\mathrm{~T} 3$ & $\mathrm{~T} 1$ & $\mathrm{~T} 2$ \\
\hline
\end{tabular}

Table 1:- Treatment assignment of goats for the entire duration of the study.

\section{Data Collection}

The data were collected by weighing of feed given to mature female goats based on feed requirements [3\% of their body weight (BW) dry matter (DM) basis] of the animals. Feed refused were collected and weighted to determine the voluntary feed intake of the animals. A ratio of $70 \%$ napier grass and $30 \%$ concentrate feeding combination were used.

\section{RESULT AND DISCUSSION}

Daily Roughage Dry Matter Intake (g/ kg Metabolic Body Weight)

Napier grass dry matter (DM) intake of goats fed with napier grass supplemented with different dietary fats (Figure 1) showed that among treatments, goat given with $5 \% \mathrm{VCO}$ in the concentrate feed got the highest NG feed intake of $465.28 \mathrm{~g}$ followed by control with $461.96 \mathrm{~g}, 5 \%$ lard with $460.56 \mathrm{~g}$ NG feed intake, $3 \%$ lard with $457.76 \mathrm{~g}$ and the lowest NG feed intake was with $3 \%$ VCO having $439.22 \mathrm{~g}$.

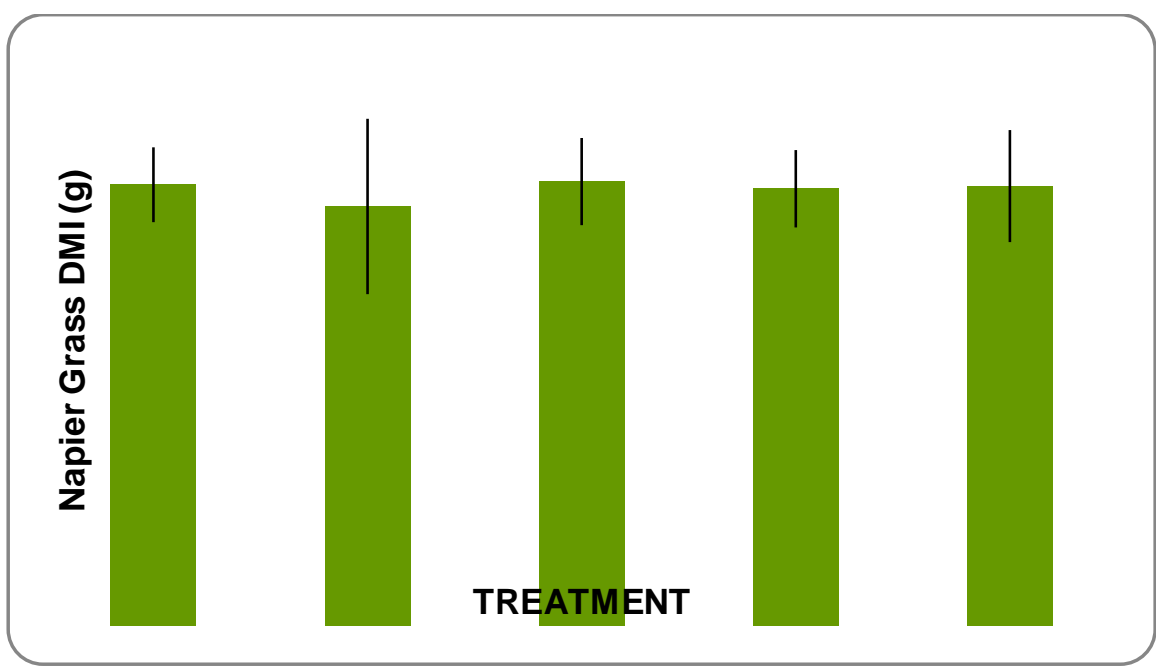

Fig 1:- Daily Roughage Dry Matter Intake (g/ kg Metabolic Body Weight)

Although more than $26 \mathrm{~g}$ was observed between the lowest to highest rumen napier grass feed intake, no significant difference $(\mathrm{P}>0.05)$ among treatment means was observed., This implies that supplementing 3 to $5 \%$ dietary fats from two different sources (VCO and Lard) in ruminant diet do not influence the $\mathrm{NG}$ feed intake of mature female goats.

\section{Daily concentrate feed intake ( $g$ DM/ $\mathrm{kg} \mathrm{MBW)}$}

Concentrate dry matter (DM) feed intake of goats fed with napier grass supplemented with different dietary fats (Figure 2) on the concentrate showed that among treatments, goat given with $5 \% \mathrm{VCO}$ in the concentrate feed got the highest concentrate feed intake of $204.9 \mathrm{~g}$ followed by goat supplemented with $3 \%$ VCO having $200 \mathrm{~g}$.

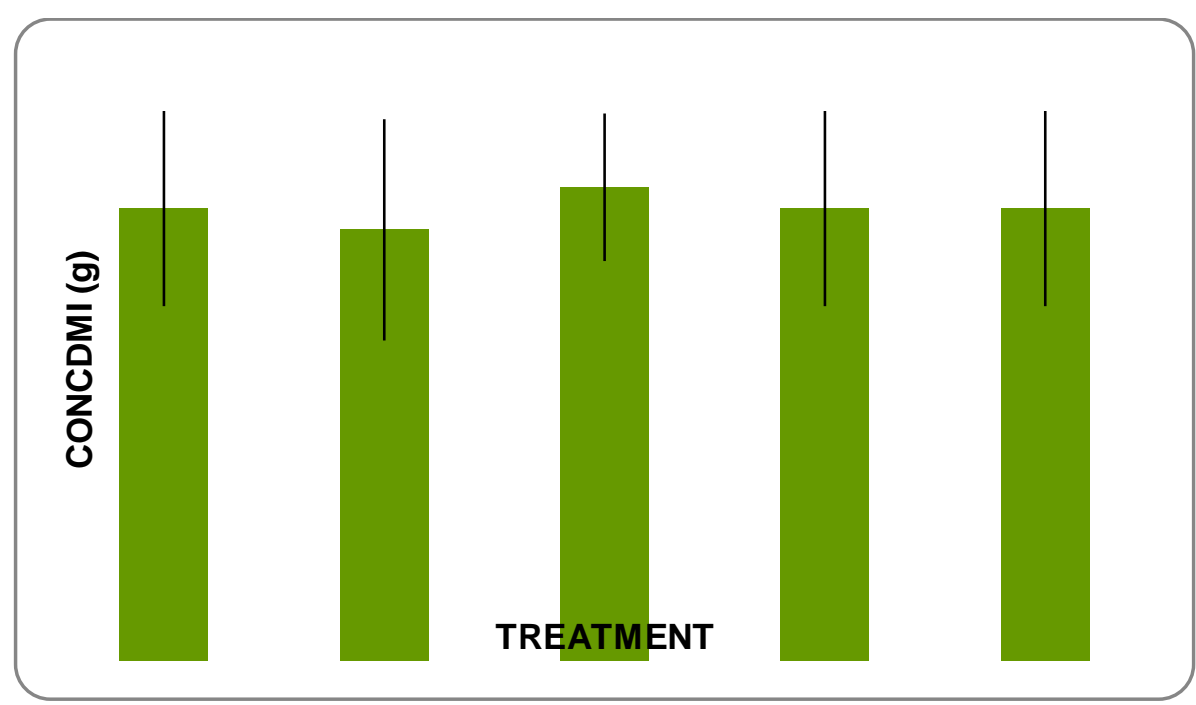

Fig 2:- Daily concentrate dry matter feed intake (g DM/kg MBW) 
No significant difference $(\mathrm{P}>0.05)$ among treatment means was observed. This implies that supplementing 3 to $5 \%$ dietary fats from two different sources (VCO and Lard) in ruminant diet do not influence the concentrate feed intake of mature female goats.
Daily total feed dry matter intake ( $g \mathrm{DM} / \mathrm{kg} \mathrm{MBW}$ )

Average total dry matter (DM) intake of goats fed with napier grass supplemented with different dietary fats on the concentrate (Figure 3) showed that among treatments, goat given with $5 \% \mathrm{VCO}$ in the concentrate feed got the highest total feed intake of $670.21 \mathrm{~g}$ followed by control with $664.42 \mathrm{~g}, 5 \%$ lard with $663.02 \mathrm{~g}$ total feed intake, $3 \%$ lard with $660.22 \mathrm{~g}$ and the lowest total feed intake was with $3 \%$ VCO having $639.21 \mathrm{~g}$.

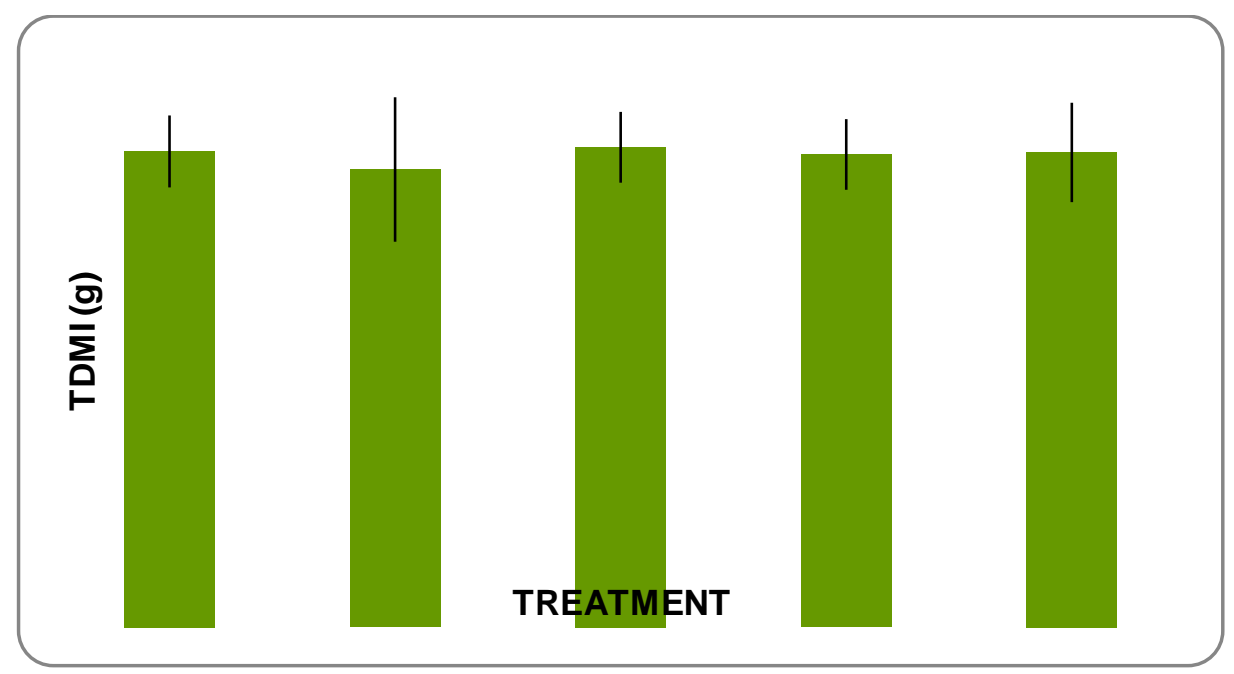

Fig 3:- Daily total feed dry matter intake (g DM/ kg MBW)

The $31 \mathrm{~g}$ difference between the highest (5\% VCO) and the lowest (3\% VCO) supplemented on the concentrate, no significant difference $(\mathrm{P}>0.05)$ among treatment means was observed., This implies that supplementing 3 to $5 \%$ dietary fats from two different sources (VCO and Lard) in ruminant diet do not influence the total feed intake of mature female goats.

The result of the experiment confirm the study of Booyens et al., (2013) that no significant difference on DMI on lambs supplemented with beef tallow and soybean oil. This similar feed intake was expected because the diet nutrient composition (especially NDF content) was the same. Differences in NDF content could affect diet digestibility and rumen fill, two important factors influencing feed intake (McDonald et al., 2002).

\section{SUMMARY AND CONCLUSION}

\section{A. Summary}

Three (3) female (rumen-cannulated goats) weighting $27.33 \pm 1.53 \mathrm{~kg}$ were housed in individual elevated metabolism stalls provided with $30 \%$ concentrate in the morning based on feed requirements (3\% of their body weight (BW) dry matter (DM) basis) of the animals. Ad libitum feeding of napier grass follows thereafter. Clean drinking water were made available all the times in the respective animal watering troughs. Complete Randomized Design (CRD) was used to evaluate the effect of different dietary treatments on goat voluntary feed intake.
All data were collected sequentially in every cycle of the study. There were 7 days lag period in every cycle for the animals to return to each natural state. On the $8^{\text {th }}$ day of every cycle animals were given different dietary treatment. Voluntary feed intakes were recorded for 3 days. This was done on the $11^{\text {th }}$ to $13^{\text {th }}$ day of feeding trial ( 3 days after treatment).

The data were collected by weighing of feed given to mature female goats based on feed requirements [3\% of their body weight (BW) dry matter (DM) basis] of the animals. Feed refused were collected and weighted to determine the voluntary feed intake of the animals. The following were data collected, daily roughage dry matter intake (g/ kg metabolic body weight), daily concentrate feed intake (g DM/kg MBW) and daily total feed dry matter intake (g DM/ kg MBW).

All data collected showed no significant difference ( $\mathrm{P}$ $>0.05$ ) among treatment means was observed. This implies that supplementing 3 to $5 \%$ dietary fats from two different sources (VCO and Lard) in ruminant diet do not influence the roughage, concentrate and total feed intake of mature female goats.

\section{B. Conclusion}

This study showed that dietary fats supplementation of either virgin coconut oil or lard at a maximum of $5 \%$ level did not influence the response the roughage, concentrate and total feed intake of mature female goats. 


\section{REFERENCES}

[1]. GOMEZ, A. AND GOMEZ K. 1992. Statistical Procedures for Agricultural Research. An International Rice Research Institute Book A WileyIntersclence Publication John Wiley \& Sons.

[2]. HESS BW. , MOSS GE. AND RULE DC. 2008. A decade of developments in the area of fat supplementation research with beef cattle and sheep. J Anim Sci. Apr, 86 (14 Suppl):E188-204. DOI: $10.2527 /$ jas.2007-0546.

[3]. K.E. BOOYENS1, O.B. EINKAMERER1, H.J. VAN DER MERWE1, A. HUGO2, S.C. SLIPPERS3 \& M.D. FAIR1., 2013. The effect of dietary lipid saturation and antioxidant source on the nutrient digestibility of lamb finishing diets. South African Journal of Animal Science, 43 (Issue 5, Supplement $1)$.

[4]. MCDONALD, P., EDWARDS, R.A., GREENHALGH, J.F.D. \& MORGAN, C.A., 2002. Animal Nutrition. 6th Edition. Pearson Prentice Hall.

[5]. SAS institute Inc., 2003. SAS User's Guide, Version 9.1, second ed. SAS Institute Inc. Cary, NC. 